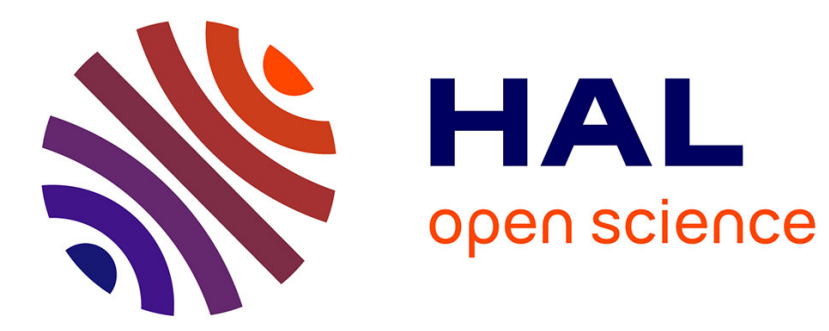

\title{
Dislocation images in high resolution scanning electron microscopy
}

\author{
R.M. Stern, S. Takashima, H. Hashimoto, S. Kimoto, T. Ichinokawa
}

\section{To cite this version:}

R.M. Stern, S. Takashima, H. Hashimoto, S. Kimoto, T. Ichinokawa. Dislocation images in high resolution scanning electron microscopy. Revue de Physique Appliquée, 1974, 9 (2), pp.385-388. 10.1051/rphysap:0197400902038500 . jpa-00243791

\section{HAL Id: jpa-00243791 https://hal.science/jpa-00243791}

Submitted on 1 Jan 1974

HAL is a multi-disciplinary open access archive for the deposit and dissemination of scientific research documents, whether they are published or not. The documents may come from teaching and research institutions in France or abroad, or from public or private research centers.
L'archive ouverte pluridisciplinaire HAL, est destinée au dépôt et à la diffusion de documents scientifiques de niveau recherche, publiés ou non, émanant des établissements d'enseignement et de recherche français ou étrangers, des laboratoires publics ou privés. 


\title{
DISLOCATION IMAGES IN HIGH RESOLUTION SCANNING ELECTRON MICROSCOPY
}

\author{
R. M. STERN \\ Department of Physics, Polytechnic Institute of Brooklyn, N. Y. 11201, U. S. A. \\ S. TAKASHIMA, H. HASHIMOTO and S. KIMOTO \\ JEOL Ltd., Tokyo, Japan \\ T. ICHINOKAWA \\ Department of Applied Physics, Waseda University, Shinjukuku-ku, Tokyo, Japan
}

\begin{abstract}
Résumé. - Des images de dislocations dans des échantillons minces de molybdénite ont été obtenues avec un microscope électronique à balayage, équipé d'un filament conventionnel, suivant les deux modes : électrons transmis, électrons rétrodiffusés. Sur des cristaux épais on n'observe par contre que le contraste des marches et autres imperfections superficielles.
\end{abstract}

\begin{abstract}
Dislocation images in the high resolution scanning electron microscope with conventional filament have been obtained in transmission and back scattering modes from thin molybdenite crystals. Thick crystals show overwhelming topology contrast from surface steps and imperfections.
\end{abstract}

The previous article presented arguments for developing scanning electron microscope techniques at intermediate energies, for the study of the details of crystal surfaces. In this article we present a series of images obtained from thin and thick molybdenite samples, using the JSM-50 A microscope, with the object of demonstrating further observations of dislocation contrast in a series of different imaging conditions [1].

Figure 1 shows the schematic arrangement of a typical SEM. Three images are possible : back scattered elastic, made by the P-N junction annular detector having a solid angle of $0.9 \pi$ radians ; back scattered inelastic (total secondary) images using a conventional secondary electron detector (in this case having less than optimal collection efficiency); and transmitted image contrast using a detector below an aperture on the exit side of the sample. This latter detector itself has a sufficiently small aperture so that it can be used to obtain either the bright field image, or by displacing the collector to one side and intercepting one of the diffracting beams, a dark field image can be obtained. In addition, by means of a pair of scanning coils located below the sample (not shown), the transmitted diffraction pattern can be obtained.

Figure 2 shows the transmitted (a), back reflected elastic $(b)$ images from a relatively thin molybdenite sample (as judged from the transmitted diffraction pattern $(c)$ ). Similar features can be found on the two images, although it is obvious that the resolution in the back scattered image is 3-5 times poorer than for the transmitted image. Figure 3 shows a similar pair of images, from a thicker sample (as indicated by the presence of Kikuchi lines in the diffraction pattern), having about the same type of dislocation distribution (as indicated by the transmission image). Certain of the dislocation images can be distinguished in the back scattered image, but it should be noted that the resolution in the thick sample is further reduced by a factor of two, as measured by the image widths of some of the dislocation lines. In both cases the transmission images are predominantly of dark contrast, while the back scattered images show both dark and light contrast.

Figure 3 shows the transmitted bright field $(a)$, transmitted dark field $(b)$, back scattered elastic $(c)$ and diffraction pattern $(d)$ for a relatively thick molybdenite sample. There are several dislocation images in the back scattered mode which are distinctly of excess/defect contrast, and many features can be identified in the two images, $(a)$ and $(c)$. Of additional interest is the contrast observed in the dark field : two seperate conditions can be found. There is a set of dislocations having the same (dark) contrast in both images ; there is a second set of images having dark contrast in the transmitted bright field image, but having reversed (bright) contrast in the transmitted dark field image. This is the typical observation in standard transmission electron microscopy for contrast reversal in the two beam case for dislocations lying 


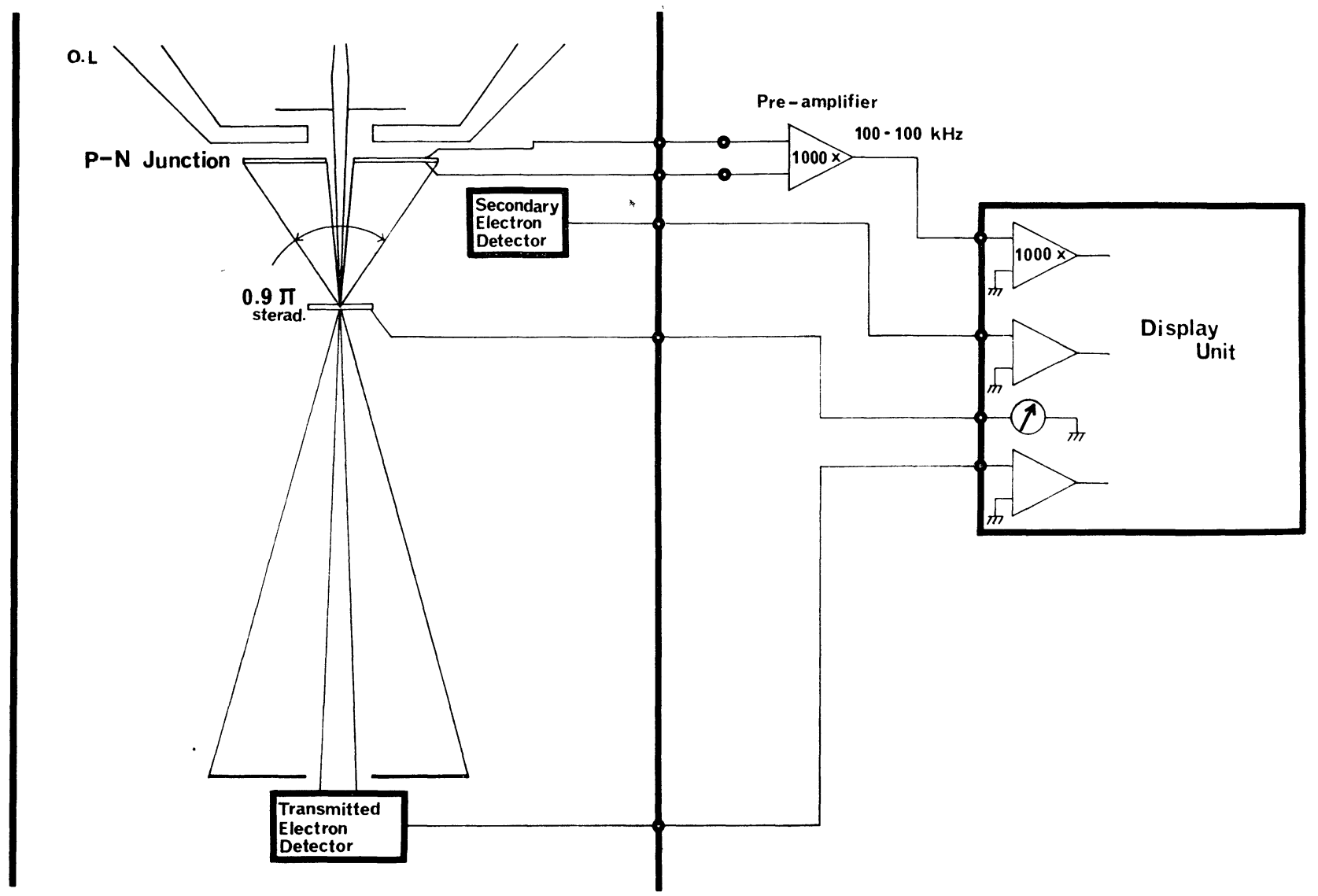

FIG. 1. - Schematic diagram of SEM showing sample and detector arrangement.
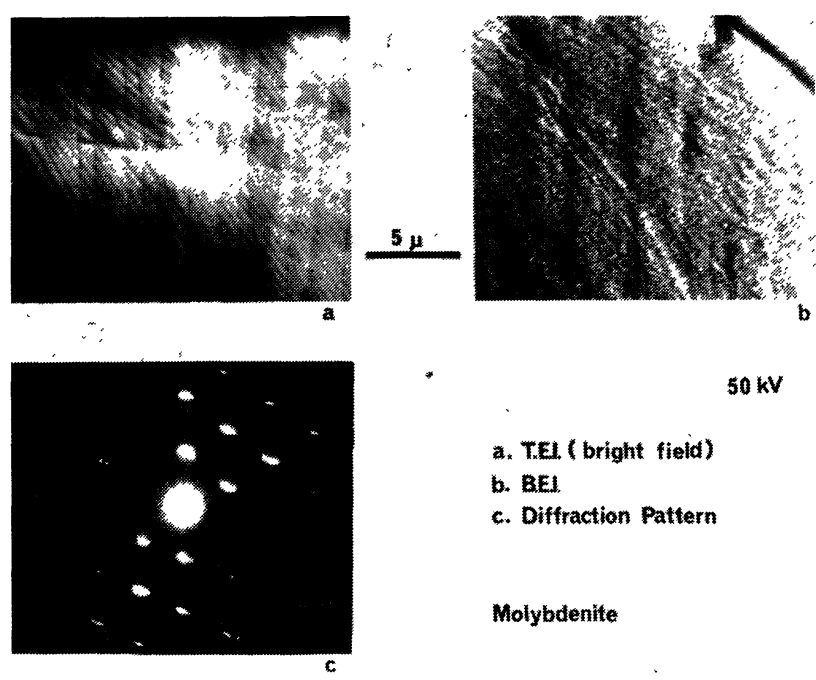

FIG. 2. - Dislocation networks at $50 \mathrm{keV}$ in molybdenite imaged in the back scattered elastic (BEI) and transmitted elastic (TEI) modes. Primary beam current : $2 \times 10^{-10} \mathrm{~A}$ (BEI) and $7 \times 10^{-10} \mathrm{~A}$ (BEI). Beam Diameter, $200 \AA$ (TEI) and $300 \AA$ (BEI). Back scattered signal across a dislocation image $2 \times 10^{-14}$ A. Thin crystal.

near to the exit surface of the crystal [2]. This is further evidence, although none additional is needed, as to the correspondence between standard and scanning electron microscopy.

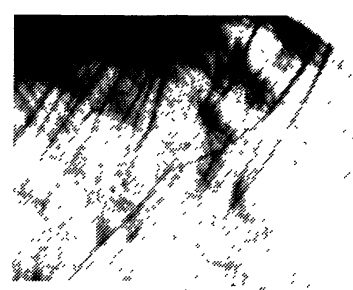

TEI bright held

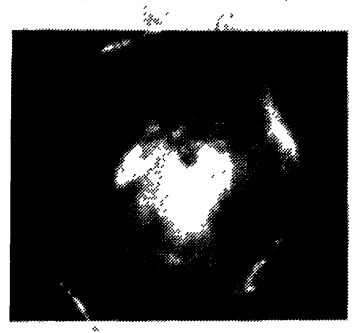

Diffraction pattern

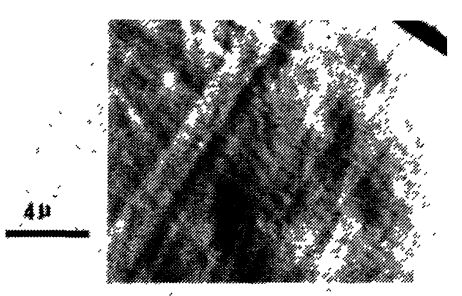

BE

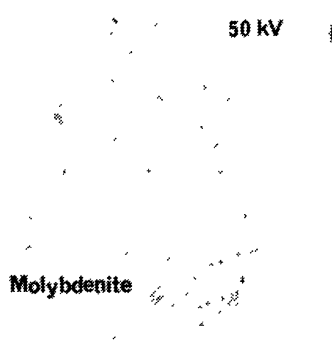

FIG. 3. - Similar images to figure 1, except in a thicker crystal (as seen by comparison of the diffraction patterns in each case).

The good agreement between observations and theory, for the excess/defect nature of dislocation contrast measured in back scattering [3], is probably due to the fact that the samples observed here are thin : there is contrast in the back scattered signal due in part to current conservation and the presence of 


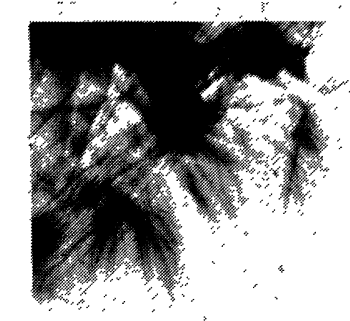

A Tel bright field

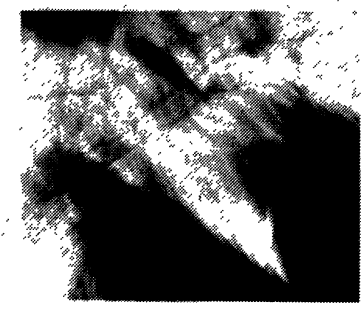

TEI dark field

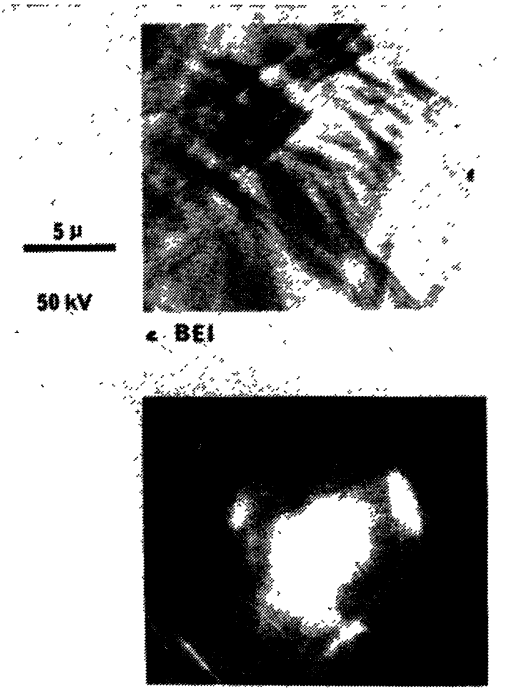

- Diffraction pattern

FIG. 4. - Similar images to figures 1 and 2, with the addition of a dark field image. This image shows the identical features as the bright field image, with the exception that one dislocation detwork shows reversed contrast.

a strong transmitted signal as well. In addition, molybdenite may be an ideal, and somewhat unique material because of the large magnitude of the extinction lengths for typical reflections : large extinction lengths are comparable with good image formation in the back scattered mode with relatively large beam dimensions (as is the case in these observations). In addition, the primary extinction length in this material may relatively long, thus making many dislocations effectively near to the upper crystal surface. A proper test of the theory for back scattering defect contrast would be the observation of dislocation images in thick (i. e. semi-infinite) crystals. Figure 5 shows an attempt, in this series of measurements, to obtain back scattered dislocation images from thick crystals. In this case the crystal was suffiicently thick so that no transmitted signal could be detected. The back scattered image (BEI) as detected with the P-N junction, and the back scattered inelastic image (SEI) obtained with the entire inelastic secondary current are shown to be almost identical, feature for feature. All of the contrast appears to be associated with surface topology : steps and tear lines. There is no evidence of any of the dislocation structure shown in figures 2-4 and in the figures of reference [1]. These images are taken at $20 \mathrm{keV}$. If the beam energy is raised to $40 \mathrm{keV}$ one additional feature appears : a set of parallel (tram) lines running diagonally across the image. These lines remain a striking feature of the image even when the sample is tilted through a large angle $\left(25^{\circ}\right)$. Although their origin is unknown, the do apparently represent a feature present in the interior of the crystal, as opposed to the other surface features.

There are two possible explanations for the absence of dislocation images in figure 5 from the thick

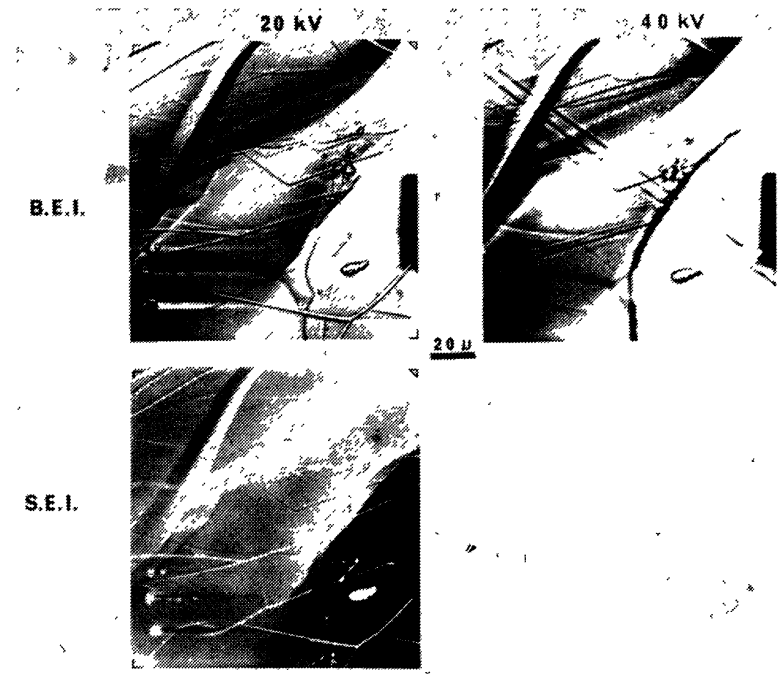

Fig. 5. - Observation in a thick crystal : Back Scattered Elastic Image (BEI) and back scattered secondary electron image (SEI) at $20 \mathrm{keV}$. All the contrast, which is identical in both images, can be attributed to surface topology. In addition, an image at $40 \mathrm{keV}$ is shown, which exhibits contrast due to an internal feature not present at $20 \mathrm{keV}$. Beam divergence for all images $2.6 \times 10^{-3} \mathrm{sr}$, Scan times $50 \mathrm{~s} /$ frame in transmission, $100 \mathrm{~s} /$ frame for back scattered elastic image. Filament brightness $3 \times 10^{5} \mathrm{~A} / \mathrm{cm}^{2}$-sr.

sample. The sample preparation is somewhat different than that for a thin sample which is multiply cleaved with pressure sensitive tape : a process which perhaps introduces the dislocations observed. On the other hand, the signal across a dislocation in figures $2-4$ in the back scattering mode is of the order of $2 \times 10^{-14} \mathrm{~A}$. In the case of figure 5 , the signal for the topology contrast is considerably larger, and hence the image processing used in this figure may prevent the detection of any dislocation contrast at all. It is clear that further observations on thick samples must be made before this question can be resolved.

One additional question can be posed : why is the surface topology contrast so high in the thick crystal case : there is no evidence for such contrast in the case of thin crystals of figures 2-4. There are two possibilities : either the direction of the surface normal plays a very important role in the thick crystal boundary condition (the surface normal is a parameter equivalent to the incident beam direction in a two dynamical model), or the step height is sufficiently large so that the specular reflection from the vertical section of surface is sufficient to scatter the beam through an angle large enough to produce the observed contrast. It should be pointed out that the total back scattered current is proportional to thickness of the crystal, and is therefore relatively large in this case, compared to the thin crystal case : the presence of the surface step therefore produces a relatively large variation in the background signal (which appears as step contrast) in the thick sample. 
The SEM back scattered images presented here are evidence for the ability of an instrument with conventional filament to produce dislocation images of the expected contrast, from, thin crystals of molybdenite. The details of the requirements on beam divergence and diameter, incident energy and current, and detector characteristics, as well as sample characteristics, which will permit the observation of dislocation in the back scattering mode, from thick (i. e. solid) samples, however remain undetermined [3], [4].

\section{References}

[1] Stern, R. M., Ichinokawa, T., Takashima, S., Hashimoto, H. and Кімото, S., Acta Phil. Mag. 26 (1972) 1495.

[2] See for example the several papers on application of scanning electron microscopy in, Proceedings of the Third International School of Electron Microscopy, Ettori Majorana, Ed. by E. Ziccici and U. Valdre, North Holland, 1974.
[3] See articles listed under reference [12] of the preceding paper, especially Clarke, D. R. and Howie, A., Phil. Mag. 24 (1971) 959.

Spencer, J. P., Humphreys, C. J. and Hirsch, P. B., Phil. Mag. 26 (1972) 193.

[4] The authors are indebted for discussions with A. Howie, D. R. Clarke, C. Humphreys, and A. Gervais. 